\title{
Delineation of seismic source zones based on seismicity parameters and probabilistic evaluation of seismic hazard using logic tree approach
}

\author{
K S VIPIN ${ }^{1, *}$ and T G Sitharam ${ }^{2}$ \\ ${ }^{1}$ Previously, Post Doctoral Fellow, Indian Institute of Science, Bangalore 560 012, India. \\ ${ }^{2}$ Department of Civil Engineering, Indian Institute of Science, Bangalore 560 012, India. \\ *Corresponding author.e-mail: ks.vipin@gmail.com
}

The delineation of seismic source zones plays an important role in the evaluation of seismic hazard. In most of the studies the seismic source delineation is done based on geological features. In the present study, an attempt has been made to delineate seismic source zones in the study area (south India) based on the seismicity parameters. Seismicity parameters and the maximum probable earthquake for these source zones were evaluated and were used in the hazard evaluation. The probabilistic evaluation of seismic hazard for south India was carried out using a logic tree approach. Two different types of seismic sources, linear and areal, were considered in the present study to model the seismic sources in the region more precisely. In order to properly account for the attenuation characteristics of the region, three different attenuation relations were used with different weightage factors. Seismic hazard evaluation was done for the probability of exceedance (PE) of $10 \%$ and $2 \%$ in 50 years. The spatial variation of rock level peak horizontal acceleration (PHA) and spectral acceleration (Sa) values corresponding to return periods of 475 and 2500 years for the entire study area are presented in this work. The peak ground acceleration (PGA) values at ground surface level were estimated based on different NEHRP site classes by considering local site effects.

\section{Introduction}

Recent studies by Kumar et al. (2007) show that the Indian subcontinent was one of the fastest moving plates before its collision with the Eurasian plate. Indian plate has attained a very high speed on 18-20 $\mathrm{cm} \mathrm{yr}^{-1}$ before the collision with Eurasian plate and after this the speed reduced to 2-4 $\mathrm{cm} \mathrm{yr}^{-1}$. One of the main reasons attributed for this high speed of Indian plate is the low plate thickness (Kumar et al. 2007). The lithospeheric thickness of the continental portion of Australia and South Africa are in the range of $180-300 \mathrm{~km}$ whereas the thickness of Indian plate is in the range of $80-100 \mathrm{~km}$. The movement of Indian plate in the NEE direction has also been reported by Sridevi (2004). Gangrade and Arora (2000) have reported that the accumulation of seismic energy in the peninsular region of India may lead to earthquakes of significantly high magnitude. There are about 12 earthquakes of moment magnitude higher than 6 has been reported in peninsular India. The deadliest continental shield earthquake was also reported in the peninsular India (Bhuj, 26 January 2001).

The seismic hazard is commonly evaluated using two different methodologies: deterministic and probabilistic approach. The deterministic approach

Keywords. Source zone; PSHA; logic tree; site response; PHA; PGA; Sa; local site effects. 
considers the worst earthquake occurrence scenario for the evaluation of the seismic hazard. This method is commonly adopted for the evaluation of seismic hazards for critical structures like nuclear power plants, big dams, etc. However, the uncertainties related to the location, magnitude, recurrence rate of earthquakes and attenuation of seismic waves are not considered in this approach. In the Probabilistic Seismic Hazard Approach (PSHA) (Cornell 1968) all the above-mentioned uncertainties are considered and nowadays this is the most widely adopted technique for the evaluation of seismic hazard. In the present work, the seismic hazard of south India was evaluated using the probabilistic approach.

\section{Study area}

South India $\left(8.0^{\circ}-20^{\circ} \mathrm{N} ; 72^{\circ}-88^{\circ} \mathrm{E}\right)$ is a part of the peninsular Indian continental shield region. Even though many studies have highlighted the need for detailed seismic study of southern peninsular India, no detailed seismic hazard analysis has been done for the entire south India. In this study, the study area selected is between latitude $8^{\circ}-20^{\circ} \mathrm{N}$ and longitude $72^{\circ}-88^{\circ} \mathrm{E}$ (figure 1). Seismic study area covers about $300 \mathrm{~km}$ from the boundary of study area (Regulatory Guide 1.165 (1997)) and this is shown in figure 1 . The study area consists of five states, viz., Kerala, Tamil Nadu, Karnataka,

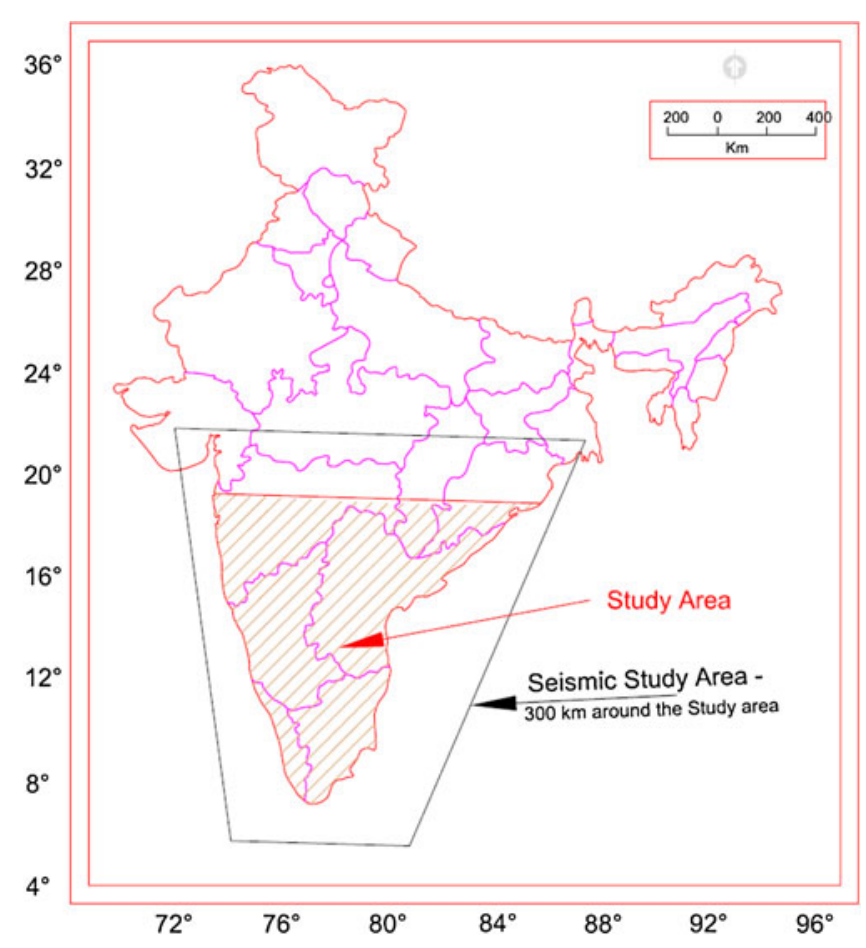

Figure 1. Study area and seismic study area.
Andhra Pradesh and Goa. The union territory of Pondicherry and some parts of the states of Maharashtra, Orissa and Chhattisgarh also fall in the study area.

A map showing various geotectonic feature of south India (Indian peninsula) like, major fault zones, thrusts, structural trends, granitic intrusions and the various lithotectonic provinces was presented by Valdiya (1973). The main geological features of peninsular India are shown in figure 2 . The important tectonic constituents of the peninsular Indian region includes the South Indian Granulite Terrain (SIGT), the Dharwar craton (DC), the Cuddapah basin (CB), the Godavari graben (GG), Deccan Volcanic Province (DVP), and the Mahanadi graben (MG) (Bhatia et al. 1997). Even though the south Indian shield is characterized by several prominent geological and geophysical features, it can be divided into three major tectonic segments: Western Dharwar craton (WDC), Eastern Dharwar craton (EDC) and Southern Granulite terrain (SGT) (Agrawal and Pandey 2004).

\section{Preparation of earthquake catalogue}

One of the most important elements of seismic hazard analysis is the compilation of the earthquake catalogue in the study area. Earthquakes which are occurring outside the study area will also contribute to the seismic hazard in the study area. Hence, the past earthquake data was collected from an area which is with in a radius of $300 \mathrm{~km}$ from the boundary of the study area (Regulatory Guide 1997). Since a complete earthquake catalogue for the study area was not available, it was prepared by compiling the data from different sources till December 2006. The data were collected from sources like India Meteorological Department (IMD), International Seismological Centre (ISC), Kalpakkam Atomic Reactor, National Geophysical Research Institute (NGRI), Hyderabad, Incorporated Research Institutions for Seismology (IRIS), Earthquakeinfo, Guaribidanur Array and United States Geological Survey (USGS). Apart from this, some data was also collected from the earthquake catalogues published by different researches.

The obtained data was in different magnitude scales like as body wave magnitude $\left(m_{b}\right)$, surface wave magnitude $\left(M_{s}\right)$, local magnitude $\left(M_{L}\right)$ and the earthquake intensity scale $(I)$. For the seismic hazard analysis, these magnitudes were converted to a single magnitude scale, moment magnitude $\left(M_{w}\right)$. Magnitude conversion relations were developed for the study area using the earthquake data obtained in the present study. However, the data available 


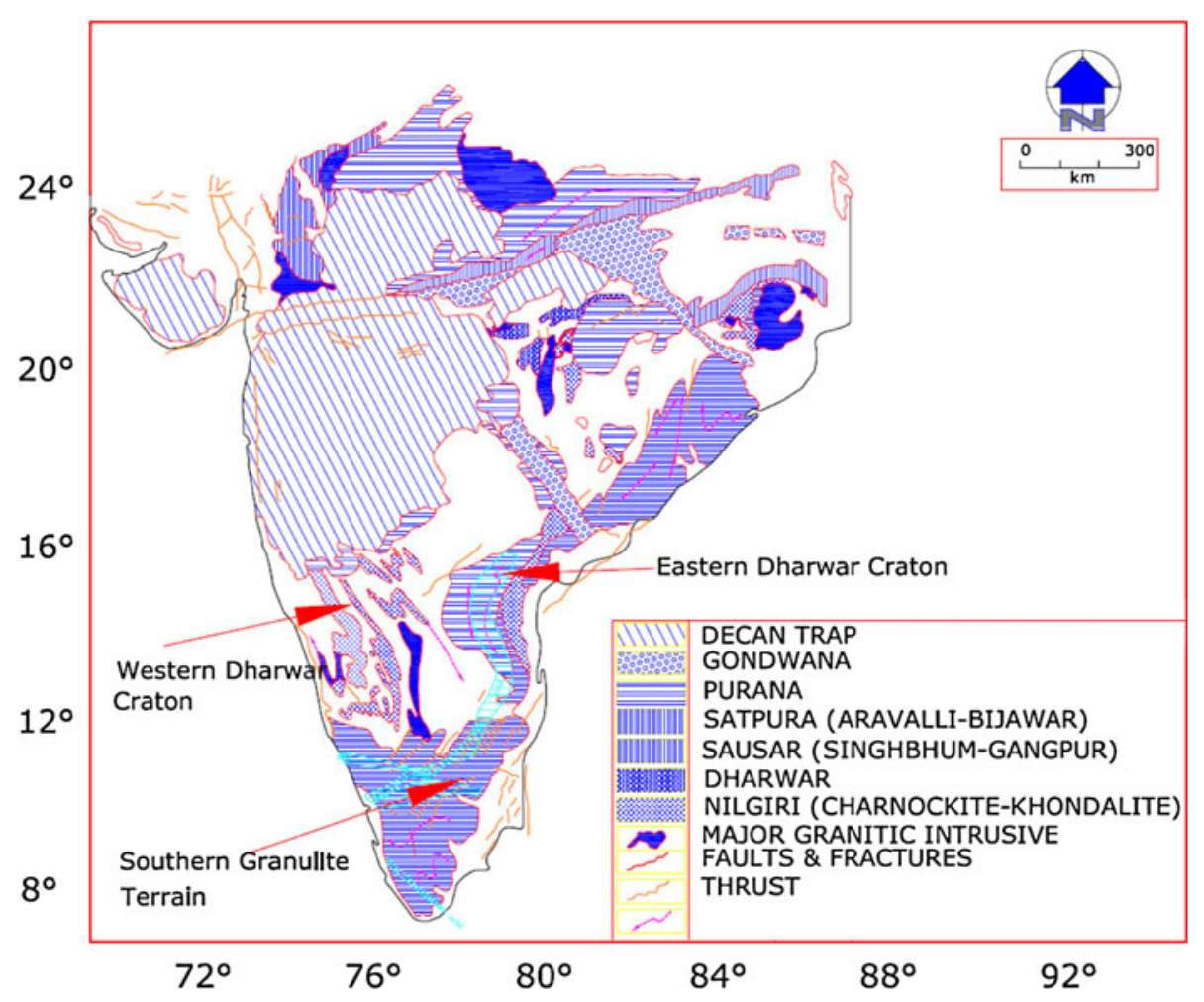

Figure 2. Geological features of peninsular India.

were very less (around 40) and the $M_{w}$ values obtained from this relation matched well with the values given by Scordilis (2006). Hence the relation suggested by Scordilis (2006) was used for the conversion of different magnitude scales to $M_{w}$. In the probabilistic seismic hazard analysis, earthquake events are assumed to follow a Poisson distribution and are independent of each other. This means that the occurrence or nonoccurrence of an earthquake should not have any effect on other earthquakes. Sometimes earthquakes with higher magnitudes will be associated with foreshocks and aftershocks and these events are related to the main shock. To remove these dependent events from the catalogue, the declustering of the events was done. There are different declustering algorithms which were developed for high seismic area. However, since the seismic activity in the study area is less, we have done the declustering based on a time window of 30 days and a distance window of $30 \mathrm{~km}$. A similar approach was adopted for declustering the events by Jaiswal and Sinha (2007) also. The declustered catalogue contains 1955 events out of which 673 events were having magnitude 4 and above. The earthquakes with magnitude 4 and above were used in the further analysis for evaluating seismic hazard. Usually the earthquakes with magnitude less than 4 may not cause any damage to structures. Moreover, by adopting this criterion the rock blats (if any) can also be filtered out from the catalogue.

\section{Seismicity parameters of the region}

The earthquake recurrence rate is expressed by the Gutenberg and Richter (1944) relation.

$$
\log _{10} N=a-b M
$$

where $N$ is the total number of earthquakes with magnitude greater than or equal to $M$ and $a$ and $b$ are the seismicity parameters for the region. The declustered earthquake data was used in evaluating the seismicity parameters ( $a$ and $b$ values) for the study area. The recurrence relation was calculated using two different methods and they form two different branches in the logic tree analysis.

The completeness of the catalogue was checked using Stepp's (1972) method. By considering the events in the complete catalogue, the seismicity parameters, i.e., $a$ and $b$ were evaluated using the method suggested by Gutenberg and Richter (1944). In the first approach, for evaluating the seismicity parameters, $a, b$ and $M_{\max }$, the entire study area was considered as a single zone. The recurrence relation obtained from this relation is given in equation (2). The frequency magnitude relation obtained for the study area as a single zone is shown in figure 3 .

$$
\log _{10} N=4.67( \pm 0.4)-0.9( \pm 0.07) M
$$

However, there will be spatial variation of these seismicity parameters across the study area. When 


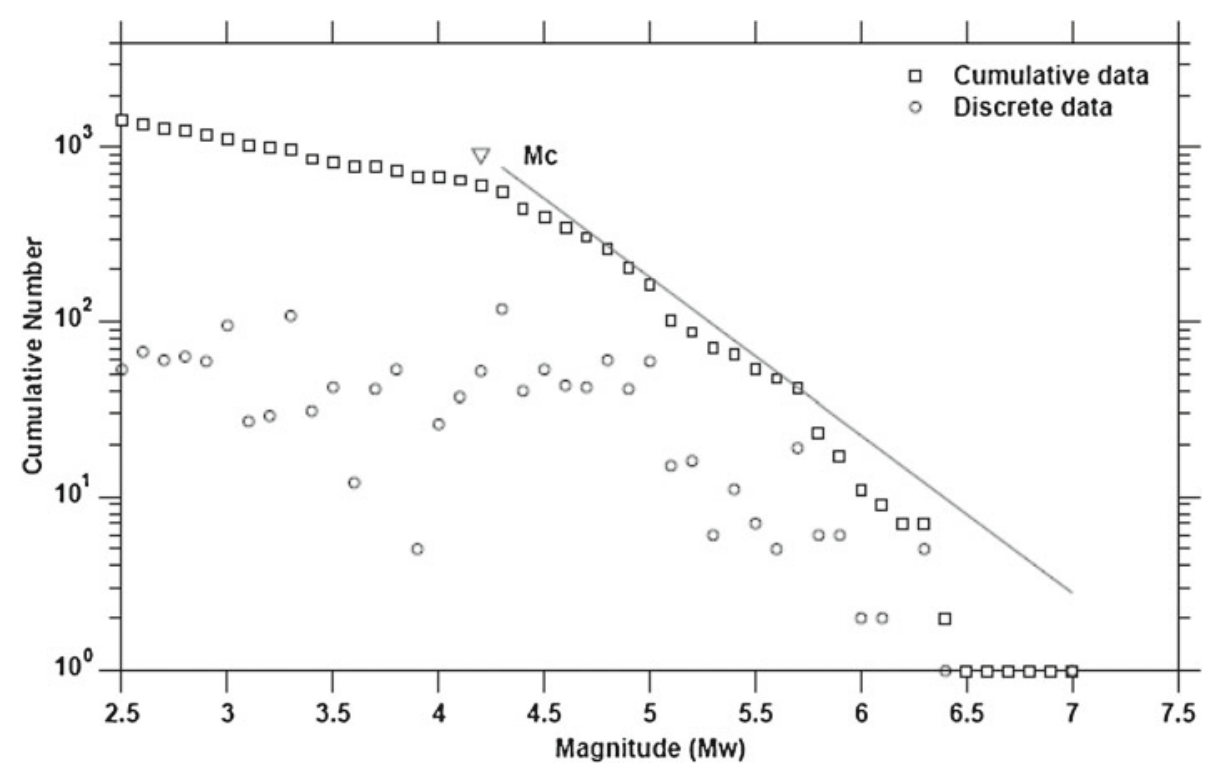

Figure 3. Frequency magnitude distribution for the entire study area as a single zone.

the study area is considered as a single zone, these variations may not be taken into to account properly. In order to consider the spatial variations of the seismicity parameters, the study area was divided into small grids of size $0.5^{\circ} \times 0.5^{\circ}$ and the seismicity parameters, $a$ and $b$, are evaluated at the centre of each of these grid cells. The evaluation of these values were done based on the magnitude of completeness $\left(M_{c}\right)$ of the catalogue and the method suggested by Wiemer and Wyss (2000). The method suggested by Wiemer (2001) was used for the evaluation of $M_{c}$ value. In this method, the evaluation is based on the assumption that the power law can approximate the frequency magnitude distribution (FMD) at $90 \%$ confidence level. The values of $a, b$ and $M_{c}$ were calculated at the centre of the grid points by considering the events with in a radius of $300 \mathrm{~km}$. The evaluation of $b$ value was done based on the maximum likelihood method (Aki 1965; Bender 1983; Utsu 1999). For this calculation, the earthquake events which are higher than the magnitude of completeness $M_{c}$ for each grid points were considered. In order to get better estimates of $b$ values, the values were evaluated for those grid points which were having at least 50 events with magnitude equal to or greater than $M_{c}$ (Utsu 1965). The uncertainties involved in evaluating $b$ value were calculated using the boot strap method (Chernick 1999).

\subsection{Spatial variation of $a, b$ and $M_{c}$ values}

The spatial variations of $M_{c}$ values are shown in figure 4 . The magnitude of completeness varies from $M_{w} 2.4$ to 4.4 and it can be observed that for majority of the region the $M_{c}$ is less than 3.5.
The magnitude of completeness along Narmada Lineament and Godavari Garben is around 3.3 and the value of $M_{c}$ is relatively high at the Deccan trap regions. The $a$ values for the study area vary from the lower value of 2.5 to the highest value of 7.5 and are shown in figure 5. For most of the study area, $a$ value is around 4 and the highest values were observed at the Deccan trap region. The spatial variations of $b$ values are given in figure 6 . The $b$ values vary from 0.3 to 1.1 and for the majority of the study area the value is around 0.5. Higher $b$ values are observed near the Deccan trap regions and at the Eastern Dhanwar craton region.

\section{Delineation of seismogenic sources based on seismicity parameters}

There has been only a little work done till now to identify and to delineate the seismic sources in peninsular India. In one of the recent works Gupta (2006) has delineated the seismic sources for India and its neighbourhood. He has delineated seismic sources based on the tectonic features and the past earthquake data. Seismic source zones in northeast India was done by Kiran et al. (2008) based on the seismicity parameters. The delineation of seismic sources in peninsular India was done by Seeber et al. (1999) and this was done based on the geology and the past seismic activity. This zoning was used by Jaiswal and Sinha (2007) in evaluating the seismic hazard parameters for the peninsular India. However, in the present study an attempt was made to delineate the seismic sources based on the seismicity parameters. Figures $4-6$ clearly indicate that there is a definite pattern in the variation of $a, b$ and $M_{c}$ values. The seismic source 


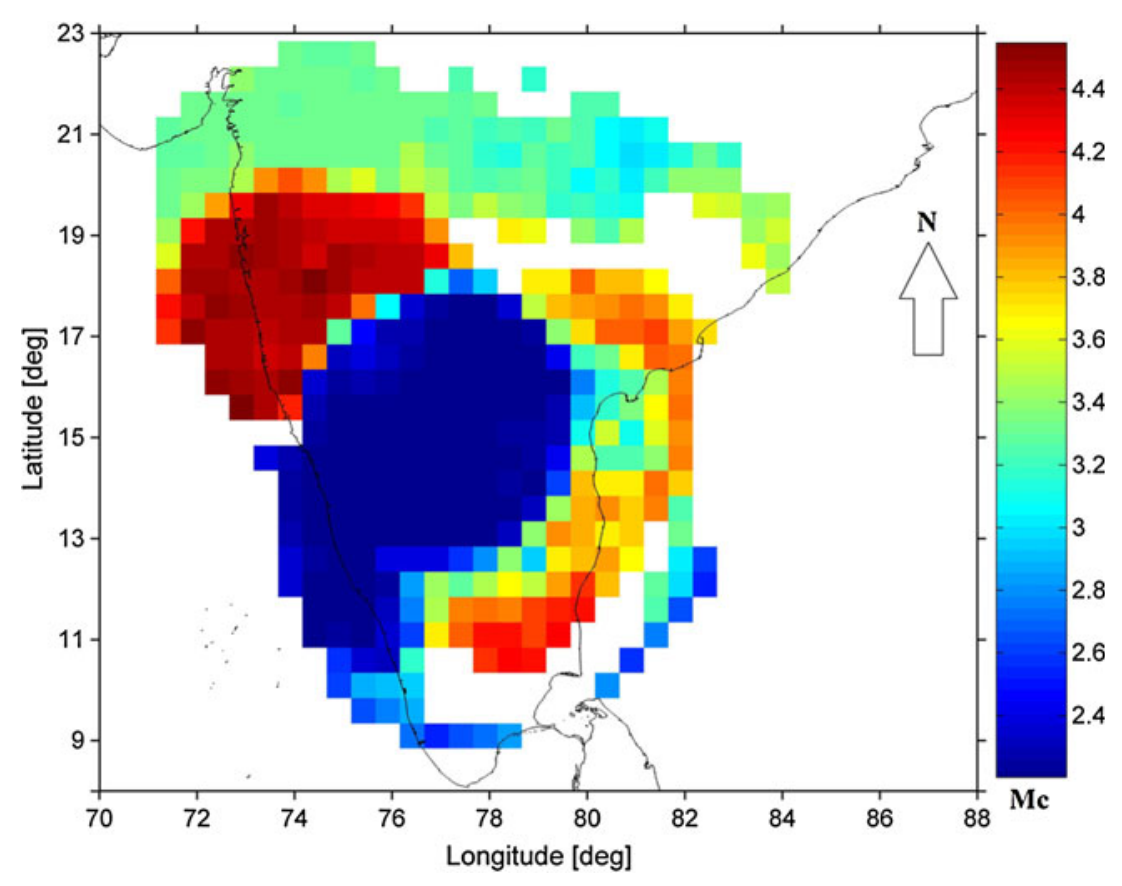

Figure 4. Spatial variation of $M_{c}$ values.

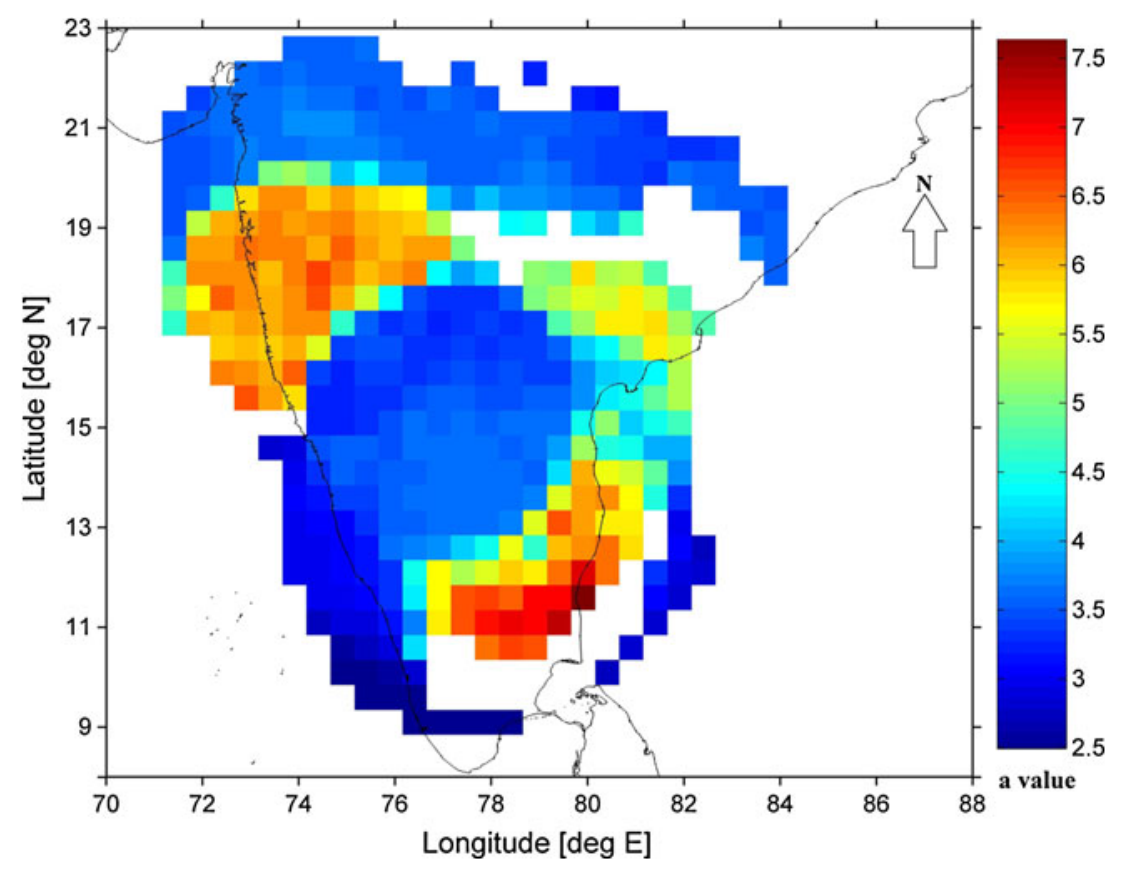

Figure 5. Spatial variation of ' $a$ ' values.

zones were delineated based on this and the five seismic source zones identified in the study area are shown in figure 7 (the variations of $b$ values are shown as background). For each of these zones, the seismicity parameters were evaluated using the frequency magnitude distribution (FMD) at $90 \%$ confidence level by considering the entire earthquake events within each zone. Maximum likelihood estimation of $M_{\max }$ was done using Cramers and Bayesian approximation (Kijko and Sellevoll
1989, 1992). The boundary details of each of these source zones along with the $b$ and $M_{\max }$ values are given in table 1 . It can be observed that the new zoning, based on the seismicity parameters, roughly matches with the seismic source zonation proposed by Seeber et al. (1999). The source zone1 of the new zoning corresponds to the Narmada Lineament and the Mahanadi Garben of Seeber et al. (1999). Moreover, the source zone-3 corresponds to Eastern Craton and Godavari Garben of 


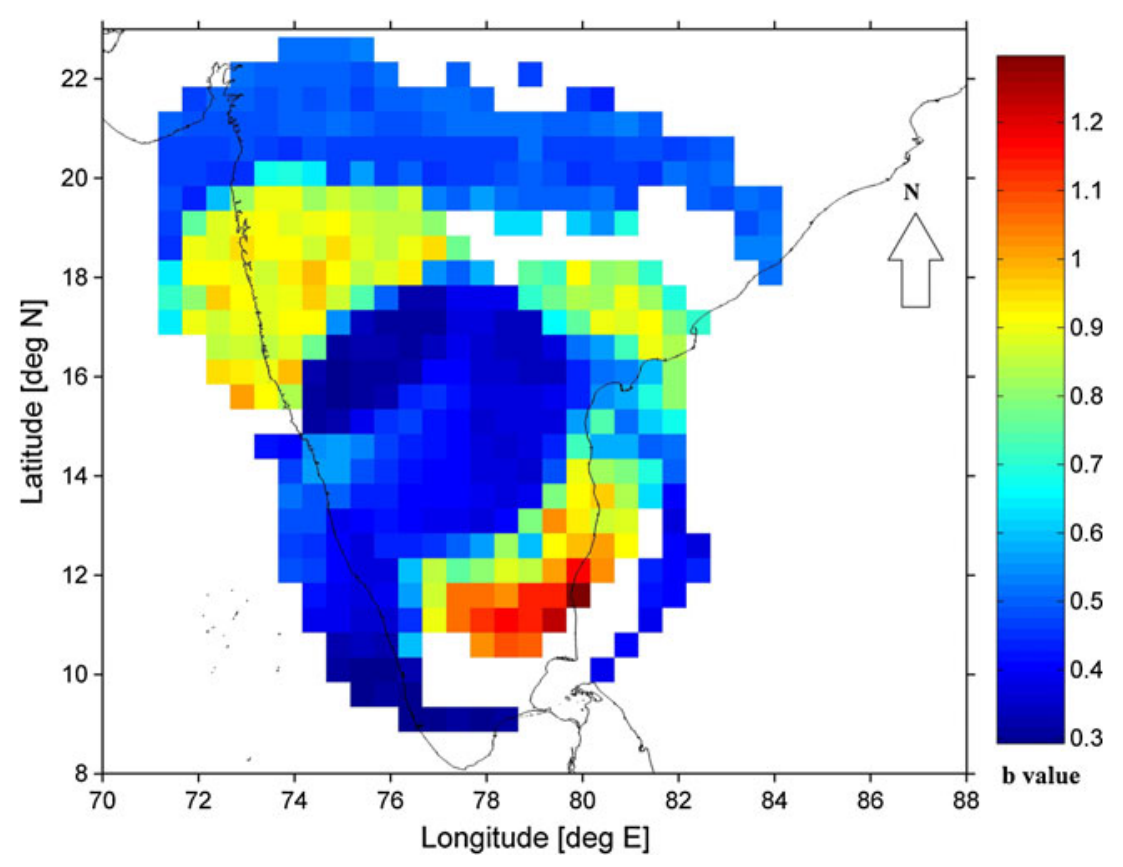

Figure 6. Spatial variation of ' $b$ ' values.

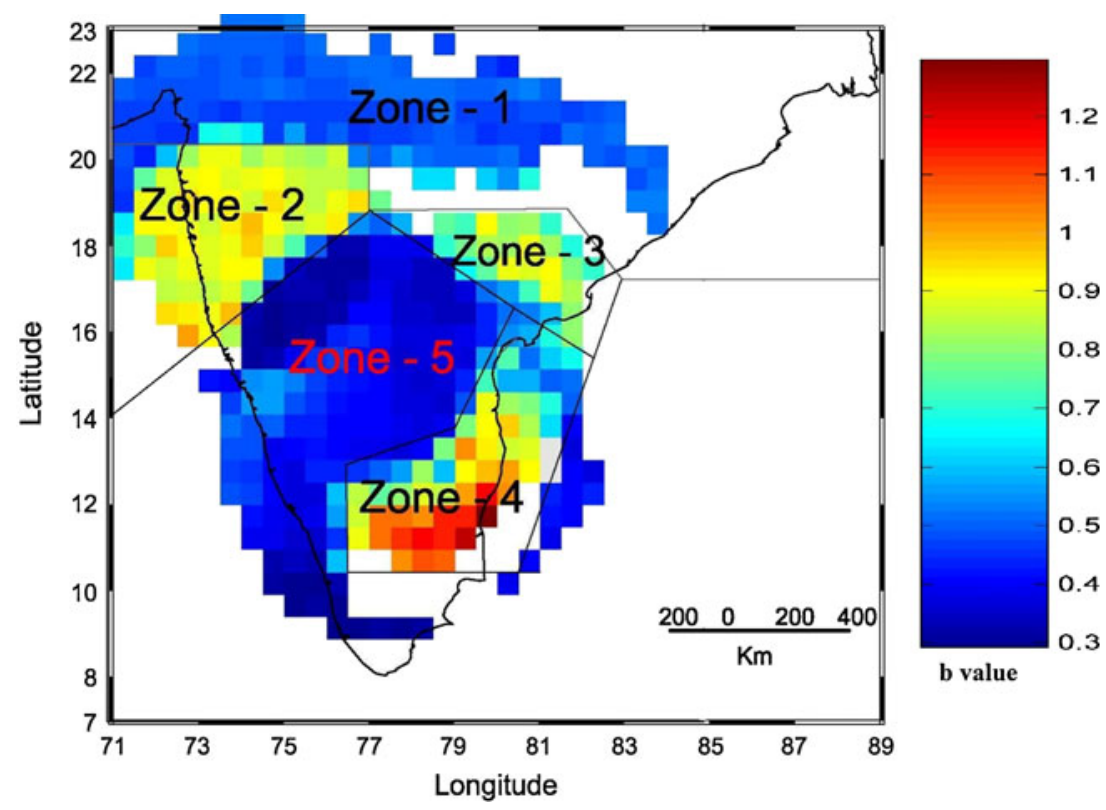

Figure 7. New seismic source zones identified based on seismicity parameters (variation of ' $b$ ' value is shown in background).

Seeber et al. (1999). In the probabilistic evaluation of seismic hazard, both the source zone models, single source zone and five source zones, were used along with the respective seismicity parameters.

\section{Seismic source characterization}

One of the major challenges in seismic hazard analysis is the identification of the vulnerable seismic sources. In the current study two types of sources were selected, linear and areal sources. The details of selection of these sources are given below.

\subsection{Linear sources}

The Geological Survey of India (GSI) has prepared the seismotectonic atlas (SEISAT 2000) after extensive studies using remote sensing technique and by geological explorations. SEISAT contains 
Table 1. Details of different seismic source zones.

\begin{tabular}{|c|c|c|c|c|c|}
\hline \multirow[b]{2}{*}{$\begin{array}{l}\text { Seismic source } \\
\text { zone no. }\end{array}$} & \multirow[b]{2}{*}{$b$ value } & \multirow[b]{2}{*}{$\sigma_{b}$} & \multicolumn{2}{|c|}{ Estimated $M_{\max }$} & \multirow[b]{2}{*}{$\begin{array}{l}\text { Geographical boundary in } \\
\text { latitude and longitude }\end{array}$} \\
\hline & & & $\begin{array}{c}\text { Cramers } \\
\text { approximation }\end{array}$ & $\begin{array}{c}\text { Bayesian } \\
\text { approximation }\end{array}$ & \\
\hline 1 & 0.48 & 0.08 & $6.33 \pm 0.4$ & $6.33 \pm 0.4$ & $\begin{array}{l}(23,71) ;(23,89) ;(16,89) ;(16,84) ; \\
\quad(19,82) ;(19,77) ;(20.5,77) ;(20.5,71)\end{array}$ \\
\hline 2 & 1.0 & 0.17 & $7.05 \pm 0.5$ & $7.04 \pm 0.5$ & $(20.5,71) ;(20.5,77) ;(19,77) ;(17,71)$ \\
\hline 3 & 0.9 & 0.46 & $6.17 \pm 0.21$ & $6.16 \pm 0.21$ & $(19,77) ;(19,82) ;(16,84) ;(15.5,82.5)$ \\
\hline 4 & 1.01 & 0.19 & $6.33 \pm 0.4$ & $6.31 \pm 0.4$ & $\begin{array}{l}(16.5,80.5) ;(15.5,83) ;(10.5,82.5) \\
\quad(10.5,76.5) ;(12.5,76.5) ;(14,79)\end{array}$ \\
\hline 5 & 0.39 & 0.02 & $6.36 \pm 0.21$ & $6.34 \pm 0.2$ & $\begin{array}{l}(19,77) ;(16.5,80.5) ;(14,79) \\
\quad(12.5,76.5) ;(10.5,76.5) ;(10.5,89) \\
\quad(7,89) ;(7,71) ;(14,71)\end{array}$ \\
\hline $\begin{array}{l}\text { Entire study area } \\
\text { as a single zone }\end{array}$ & 0.9 & 0.07 & $7.08 \pm 0.51$ & $7.04 \pm 0.5$ & $(23,71) ;(23,88) ;(6,88) ;(6,71)$ \\
\hline
\end{tabular}

the details of the faults, lineaments and shear zones in India and adjoining areas. This has been taken as an authentic reference manual for identifying the seismic sources by various researchers like, Iyengar and Ghosh (2004) for Delhi, Nath (2006) for microzonation of Sikkim Himalayas, Raghu Kanth and Iyengar (2006) for Mumbai, Anbazhagan et al. (2009) for Bangalore, Vipin et al. (2009) for south India, etc. In the present study also SEISAT was taken as the main reference for the linear seismic sources. The study area was covered in 19 sheets of SEISAT. The required pages of SEISAT were scanned and after georeferencing these digitized images, the earthquake data were superimposed on this. The sources, which are associated with earthquake events of magnitude 4 and above, were identified and were used in the hazard analysis.

Apart from this, a few more sources which were identified by researches were also used in this study. Ganesha Raj and Nijagunappa (2004) had identified seismic sources based on the remote sensing technique for the state of Karnataka. In addition to the sources given in the SEISAT, the

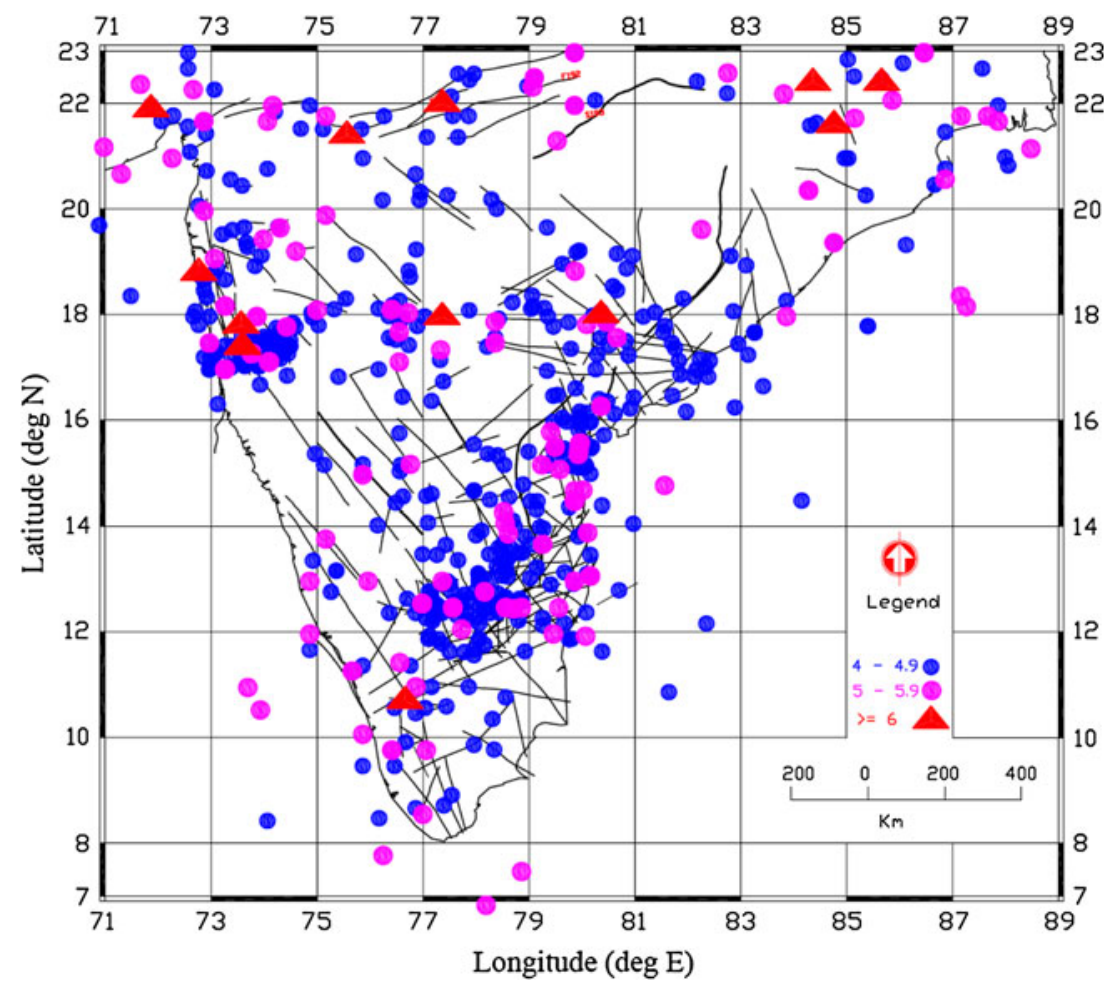

Figure 8. Details of faults considered in the seismic hazard analysis. 
seismic sources identified by Ganesha Raj and Nijagunappa (2004) were also used in the present study. Anbazhagan et al. (2009) had also considered these seismic sources in evaluating the seismic hazard analysis of Bangalore. A total of 192 linear seismic sources were identified in the study area and these were used in evaluating the seismic hazard. The maximum reported earthquake magnitude for each of the linear sources was determined (by analyzing the superimposed the earthquake data on the digitized fault map) and this value was increased by 0.5 (Iyengar and Ghosh 2004; Raghu Kanth and Iyengar 2006) to get the maximum expected earthquake magnitude for each source. The $a$ and $b$ values for seismic source zone, in which each of these linear seismic sources belong to, were assigned to these sources. The seismotectonic atlas prepared for the study area by consolidating all the faults is shown in figure 8.

\subsection{Areal sources (zoneless approach)}

There may be cases in which the seismic sources are spread over an area, like that of Koyna region. In such cases, the linear sources may not be able to give the correct picture of hazard levels. More over there may be some faults which are not yet identified. To overcome this limitation one more source model was selected in this study - areal sources. These are sources which are spread over a large area. The smoothed historic seismicity approach suggested by Frankel (1995) was adopted for smoothing the areal seismic sources. For the evaluation of seismic hazard, spatially smoothed $a$-value based on earthquakes of magnitude 4 and above were used.

While considering the areal sources, the spatial smoothing of the earthquake data was done. The first step, while considering areal sources, is the selection of grid size and the cut-off magnitude $\left(M_{\text {cut }}\right)$. A grid size of $0.1^{\circ} \times 0.1^{\circ}$ was selected in the present analysis and the number of earthquake events of magnitude greater than or equal to $M_{\text {cut }}$ were counted for each grid cell. From this value the number of earthquakes per year is calculated and this represents the maximum likelihood estimate of $10^{a}$ for that grid cell. Using this value, the recurrence rate for different magnitude intervals were calculated based on the methods suggested by McGuire and Arabasz (1990). These values $\left(10^{a}\right)$ were smoothed using a Gaussian function, given in equation (3), to get the final corrected values for each grid. This smoothing is done to account for the uncertainty associated with location of earthquake events.

$$
\widehat{n}_{i}=\frac{\sum_{j} n_{j} e^{-\Delta_{i j}^{2} / c^{2}}}{\sum_{j} e^{-\Delta_{i j}^{2} / c^{2}}}
$$

where $n_{j}$ is the number of earthquakes in the $j$ th grid cell and $\widehat{n}_{i}$ is the smoothed number of earthquakes in $i$ th cell; $c$ is the correlation distance to account for the location uncertainties and $\Delta_{i j}$ is the distance between the $i$ th and $j$ th cells. A cutoff magnitude of $M_{w}=4$ and a correlation distance of $50 \mathrm{~km}$ were used in smoothing the $a$ values. The annual rate of exceedance for a given ground acceleration level is given by

$$
\begin{aligned}
\lambda(Z>z)= & \sum_{d} \sum_{i} 10^{\left[\log _{10}\left(N_{d} / T\right)-b\left(m_{i}-m_{\mathrm{cut}}\right)\right]} \\
& \times P\left(Z>z \mid D_{d} M_{i}\right)
\end{aligned}
$$

where $d$ and $i$ are indices for distance and magnitude bins. $N_{d}$ is the total of $\widehat{n}_{i}$ values over a given hypocentral distance increment. $P\left(Z>z \mid D_{d} M_{i}\right)$ will give the probability that a PGA of $Z$ will exceed $z$, when an earthquake of magnitude $M_{i}$ occurs at a distance $D_{d}$. The seismicity parameters for the areal sources were assigned based on the seismic source zone to which it belongs to.

\section{Probabilistic evaluation of seismic hazard}

The evaluation of seismic hazard was done using probabilistic seismic hazard analysis (PSHA), which was initially developed by Cornell (1968). While doing the probabilistic analysis, the probability of exceedance of a particular ground motion level during a specific period is evaluated. The hazard curves obtained form PSHA show the variation of peak horizontal acceleration (PHA) or spectral acceleration (SA) against mean annual rate of exceedance. For calculating the seismic hazard values, the entire study area was divided into grids of size $0.1^{\circ} \times 0.1^{\circ}$ (about 10000 grid cells) and the hazard values at the centre of each grid points were calculated by considering all the seismic sources and earthquake events with in a radius of $300 \mathrm{~km}$. The hypocentral distance for all the sources were calculated for each of these grid points. In the case of linear sources, the hypocentral distance range (minimum and maximum distance) were deaggregated into small bins of $5 \mathrm{~km}$. The magnitude de-aggregation was done by dividing the magnitude range, lowest expected magnitude (in the present study it was taken as 4) and $M_{\max }$ into small magnitude bins of size 0.2 . A set of new programs were developed in MATLAB and the entire probabilistic seismic hazard analysis were carried out using these programs.

While evaluating the seismic hazard, two types of uncertainties are encountered: epistemic and aleatory. The epistemic uncertainty is due to the 
incomplete knowledge about the earthquake process and this can be reduced by acquiring more information pertaining to the earthquake process and through research. On the other hand, the aleatory uncertainty refers to the unpredictable nature of earthquake occurrence and the ground motion prediction and this cannot be reduced by further study or research. The aleatory uncertainty in the spectral acceleration prediction is given by the standard deviation of the residual error. In most of the attenuation relationships this is assumed to follow a log-normal distribution (Frank et al. 2005). While doing the seismic hazard analysis using PSHA, this aleatory uncertainty is taken into account by considering the standard deviation of residuals in the prediction equations. However, no seismic hazard method can incorporate the epistemic uncertainty in the analysis process. The adoption of logic tree approach will help in incorporating the epistemic uncertainty in the hazard analysis (Budnitz et al. 1997; Stepp et al. 2001; Bommer et al. 2005).

\section{Designing the logic tree}

In PSHA analysis, a logic tree is used to take into account the epistemic uncertainties involved in the models. In logic tree approach sum of weightage factor for all the branches at each node should be equal to unity. The logic tree model adopted for this study along with the weightage for each branch is given in figure 9. The important steps adopted in selecting different branches and their weightage values are discussed below.

\subsection{Source models}

The two types of the source models selected were linear sources and the areal sources as discussed in the previous sections. Since both models were of equal importance, the weightage given for them were 0.5 each.

\subsection{Seismic zone model}

Two types of seismic source zones were considered in this study. In the first model, the entire study area was considered as a single zone. The seismicity parameters and $M_{\max }$ were evaluated for the entire study area, as a single zone, and this was used in the analysis. In logic tree this branch was given a weightage of 0.4 . In the second model, the study area was divided into five seismic zones (table 1) and the corresponding seismicity parameters were used. The $M_{\max }$ for the areal sources were selected based on the seismic source zone to which it belongs to and for the faults the $M_{\max }$ was selected based on the maximum reported magnitude along the respective faults (as described in the previous sections).

The accuracy of evaluating $a$ and $b$ values depends on the number of earthquake events available for the analysis. Since the number of earthquake events in some of the zones were less, the single zone model was also used in the logic tree with a reduced weightage.

\subsection{Attenuation model}

One of the factors, which is having high influence on the evaluation of seismic hazard, is the ground motion prediction models. There can be considerable variation between the predicted and the actual acceleration values given by the attenuation models. Hence for reducing the epistemic uncertainties in the prediction models multiple attenuation models are used in this study. At present there is only one attenuation model available for peninsular India, which was developed by Raghu Kanth and Iyengar (2007). In addition to this two more attenuation relationships were considered in this study, one by Atkinson and Boore (2006) and the other by Toro et al. (1997). These two attenuation relationships were developed for the Eastern North America (ENA), which is also a stable continental region, like peninsular India. Based on the results of the ground motion attenuation analysis of Bhuj earthquake, Cramer and Kumar (2003) suggest that the ground motion attenuation in ENA and peninsular India are compatible. All the three attenuation relations mentioned above give the PGA at bed rock level. Since Raghu Kanth and Iyengar (2007) model was developed for the peninsular India, by considering the rock properties in this region, this relation was given the highest weightage of 0.5 in the logic tree analysis. The relation suggested by Atkinson and Boore (2006) has been developed by considering a very large database of events recorded on rock sites and this was given a weightage of 0.3 and the relation suggested by Toro et al. (1997), which is also a widely accepted attenuation relation for stable continental shield region, was given a weightage of 0.2 . The comparison of the ground motion values given by the three attenuation models for an earthquake of magnitude $M_{w}=6.5$ and focal depth $15 \mathrm{~km}$ is given in figure 10. Both Raghu Kanth and Iyengar (2007) and Toro et al. (1997) models are developed based on a point source model, i.e., the earthquake source is considered as a point. This is the major reason for agreement of PHA values obtained from these models in figure 10. Whereas the model by Atkinson and Boore (2006) is developed based on the latest concept of finite-fault model. 


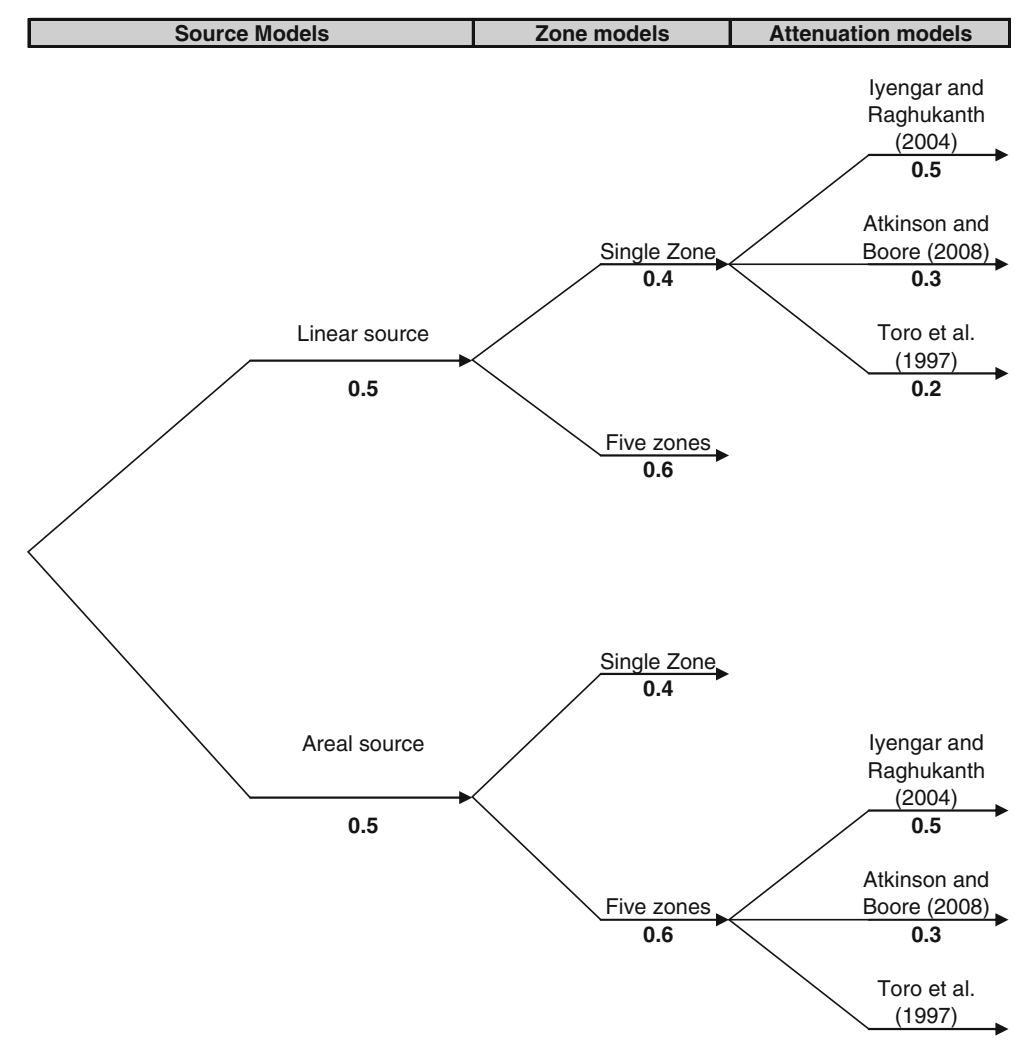

0.2

Figure 9. Logic tree structure adopted in this study.

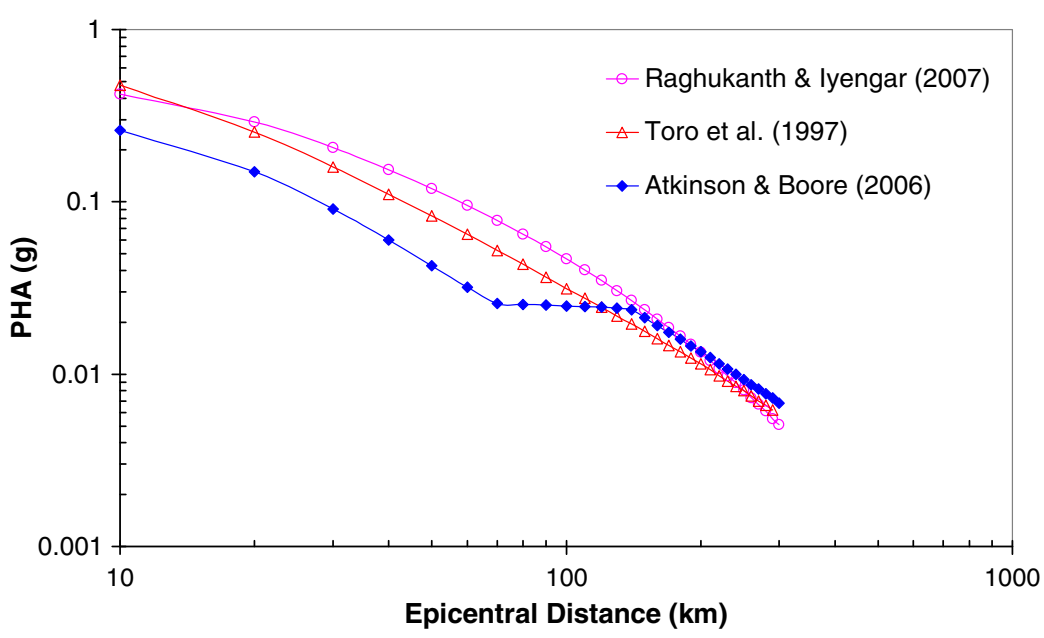

Figure 10. Comparison of PHA values given by different attenuation values for an earthquake of magnitude $M_{w} 6.5$.

\section{Site response studies}

In the previous sections, the evaluation of PHA and $\mathrm{Sa}$ values at rock levels were discussed in detail. When the seismic waves travel through the overlying soil to the ground surface the peak ground acceleration and Sa values will get changed. This amplification or de-amplification of the seismic waves depends on the type of soil overlying the bed rock. Local site conditions describe the state of the soil which lies beneath the site. One of the methods which is being widely used for classifying the site is the average shear wave velocity in the top $30 \mathrm{~m}$, commonly referred to as $V_{s}^{30}$. This method has been adopted by many codes for estimating the design ground motion at a site, after incorporating the local site conditions. There are six site classes suggested by National Earthquake Hazard Reduction Program (NEHRP) recommendations (The Building Seismic 
Safety Council (BSSC) 2001). The shear wave velocity ranges for each site class, as suggested by NEHRP, are site class A $\left(V_{s}^{30}>1.5 \mathrm{~km} / \mathrm{s}\right)$, site class B $\left(0.76 \mathrm{~km} / \mathrm{s}<V_{s}^{30} \leq 1.5 \mathrm{~km} / \mathrm{s}\right)$, site class C $\left(0.36 \mathrm{~km} / \mathrm{s}<V_{s}^{30} \leq 0.76 \mathrm{~km} / \mathrm{s}\right)$ and site class $\mathrm{D}$ $\left(0.18 \mathrm{~km} / \mathrm{s}<V_{s}^{30} \leq 0.36 \mathrm{~km} / \mathrm{s}\right)$. Site class E consists of soil profile with more than 10 feet of clay which is having a plasticity index higher than 20 or water content higher than $40 \%$ and $V_{s}^{30}<180 \mathrm{~m} / \mathrm{s}$. Site class F consists of soils like highly sensitive clays, collapsible weakly-cemented soils, etc. and these types of soils require site specific evaluations. In the present study four site classes were considered, viz., site class A to D. For estimating the surface level PGA and Sa values, the models suggested by Raghu Kanth and Iyengar (2007) were used. This model was developed using the soil profiles selected from various parts of India. Hence this was the only attenuation model used in the present study to evaluate the surface level PGA values.

\section{Results and discussions}

The peak horizontal acceleration (PHA) and spectral acceleration (Sa) values for $1 \mathrm{~Hz}$ and $10 \mathrm{~Hz}$ at rock level were evaluated using probabilistic method for the entire study area. The PHA and Sa values were evaluated for a return period of 475 years and 2500 years, which correspond to $10 \%$ and $2 \%$ probability of exceedance (PE) in 50 years. The rock level PHA values for 10\% PE in 50 years are shown in figure 11. The maximum PHA value, about $0.25 \mathrm{~g}$, was obtained at the Koyna region $\left(73.75^{\circ} \mathrm{E}\right.$ and $\left.17.5^{\circ} \mathrm{N}\right)$. As per the Indian standard

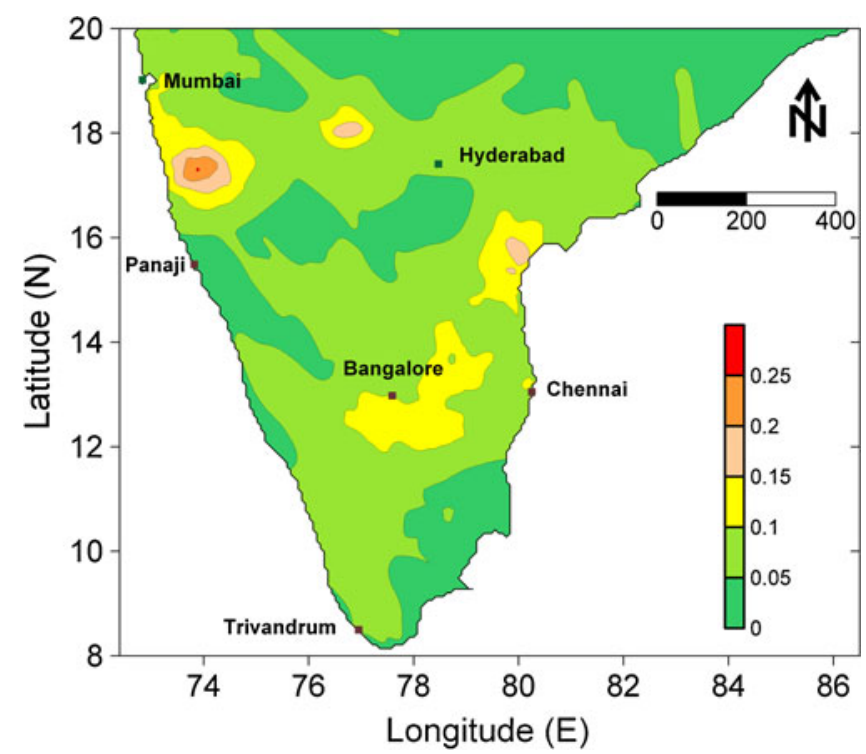

Figure 11. PHA(g) with $10 \% \mathrm{PE}$ in 50 years at bed rock level. code, BIS-1893 (2002), the Koyna region is in zone$\mathrm{IV}$, where the maximum expected ground acceleration is $0.24 \mathrm{~g}$. The PHA value obtained for regions near Bangalore $\left(77.5^{\circ} \mathrm{E}\right.$ and $\left.12.5^{\circ} \mathrm{N}\right)$ were in the range of $0.1-0.15 \mathrm{~g}$. As per BIS-1893 (2002) majority of this region falls in zone II, where the maximum expected acceleration is $0.1 \mathrm{~g}$. The maximum PHA values obtained for rest of the southern regions of the study area are less than $0.1 \mathrm{~g}$. The regions near Ongole $\left(15.494^{\circ} \mathrm{N}, 80.052^{\circ} \mathrm{E}\right)$ is having PHA values in the range of $0.15-0.2 \mathrm{~g}$, which is higher than what is specified in the seismic zonation map (BIS-1893 2002). Some regions near the southern tip of the study area (parts of Kerala and

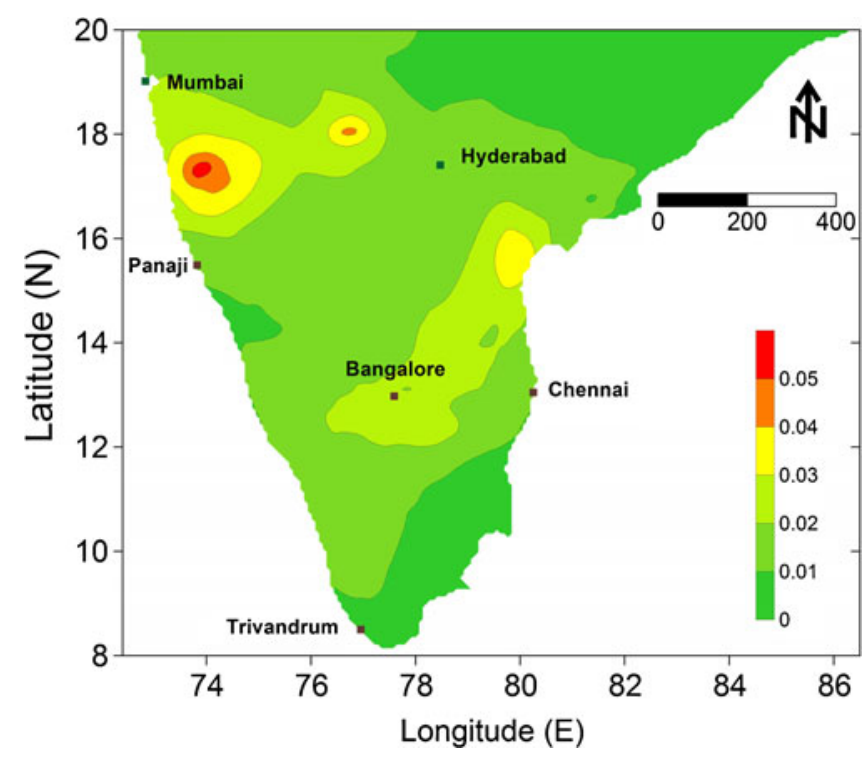

Figure 12. Sa for $1 \mathrm{~Hz}$ with $10 \% \mathrm{PE}$ in 50 years at bed rock level.

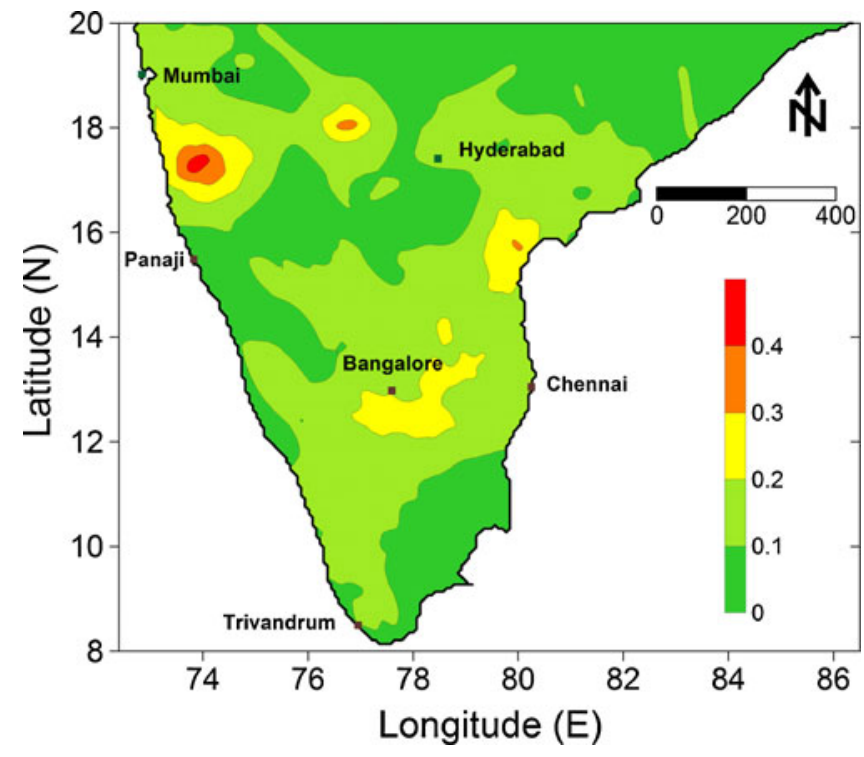

Figure 13. $\mathrm{Sa}(\mathrm{g})$ for $10 \mathrm{~Hz}$ with $10 \% \mathrm{PE}$ in 50 years at bed rock level. 
Tamil Nadu) are having a maximum of PHA value of $0.1 \mathrm{~g}$. Whereas the maximum PHA value for these regions specified in BIS-1893 (2002) is in the range of $0.1-0.16 \mathrm{~g}$. The variation of spectral acceleration values for $1 \mathrm{~Hz}$ and $10 \mathrm{~Hz}$ with $10 \% \mathrm{PE}$ in 50 years are shown in figures 12 and 13. The maximum Sa value were obtained at the Koyna region.

The PHA and Sa values were calculated for a PE of $2 \%$ in 50 years (return period 2500 years). This PHA value is generally considered for estimation of seismic margin, so that the buildings will not collapse completely, even though an earthquake of magnitude equal to the maximum credible

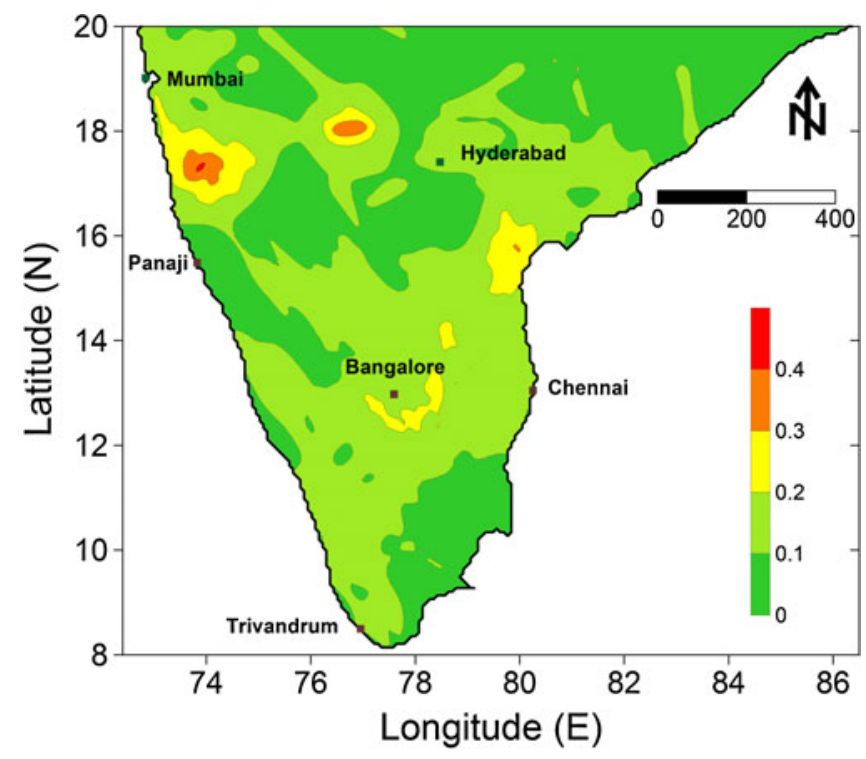

Figure 14. PHA(g) with $2 \% \mathrm{PE}$ in 50 years at bed rock level.

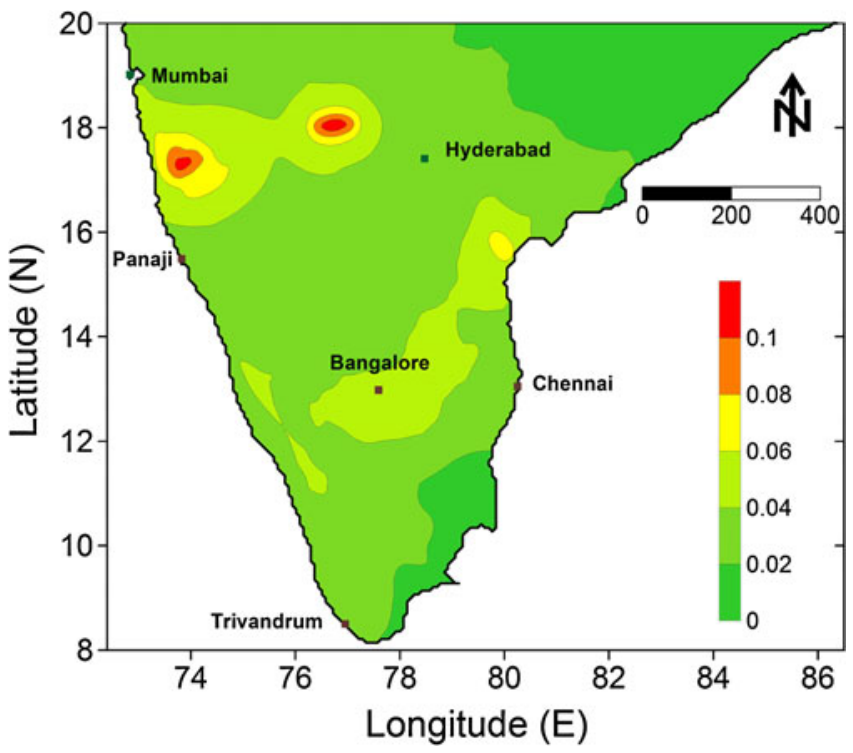

Figure 15. $\mathrm{Sa}(\mathrm{g})$ for $1 \mathrm{~Hz}$ with $2 \% \mathrm{PE}$ in 50 years at bed rock level. earthquake occurs. The spatial variation of PHA and $\mathrm{Sa}$ values for $1 \mathrm{~Hz}$ and $10 \mathrm{~Hz}$ are shown in figures 14-16 respectively. The maximum PHA and Sa values were obtained for Koyna region for a return period of 2500 years also.

The response spectrum which is having the same probability of exceedance for all the frequencies is known as uniform hazard response spectra (UHRS). UHRS will show the variation of Sa values for different frequency (period) of oscillation and will also vary for different site conditions. This will help the designers in finding the Sa values for any particular period of oscillation and for a given site condition. In the present study, UHRS was developed for five different site conditions like - bedrock, site class A, B, C and D for Mumbai and Chennai cities. For both the cities the PE considered was $10 \%$ in 50 years and the results are shown in figures 17 and 18 . These results clearly show the

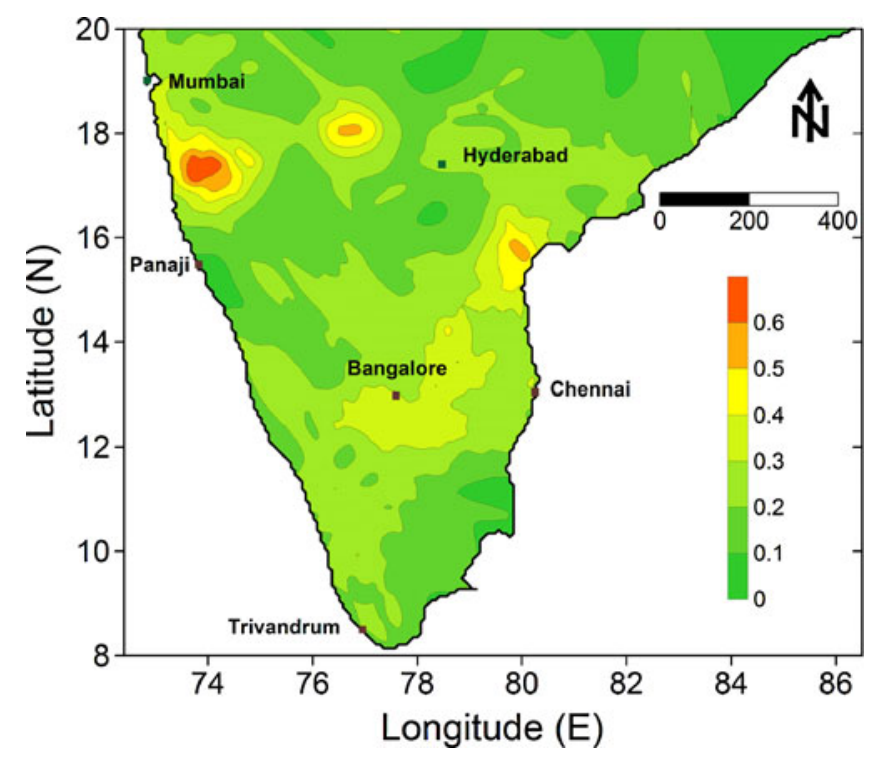

Figure 16. $\mathrm{Sa}(\mathrm{g})$ for $10 \mathrm{~Hz}$ with $2 \% \mathrm{PE}$ in 50 years at bed rock level.

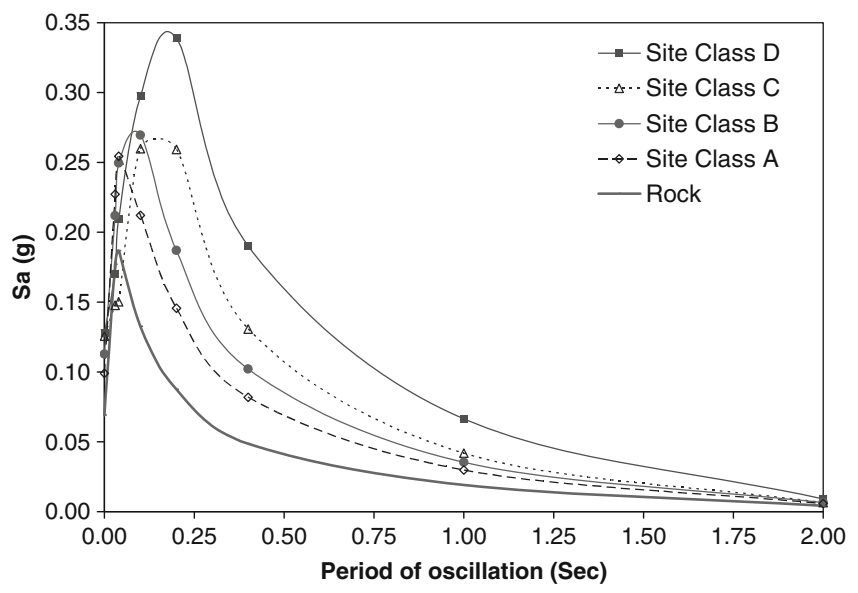

Figure 17. UHRS with $10 \% \mathrm{PE}$ in 50 years for Mumbai. 


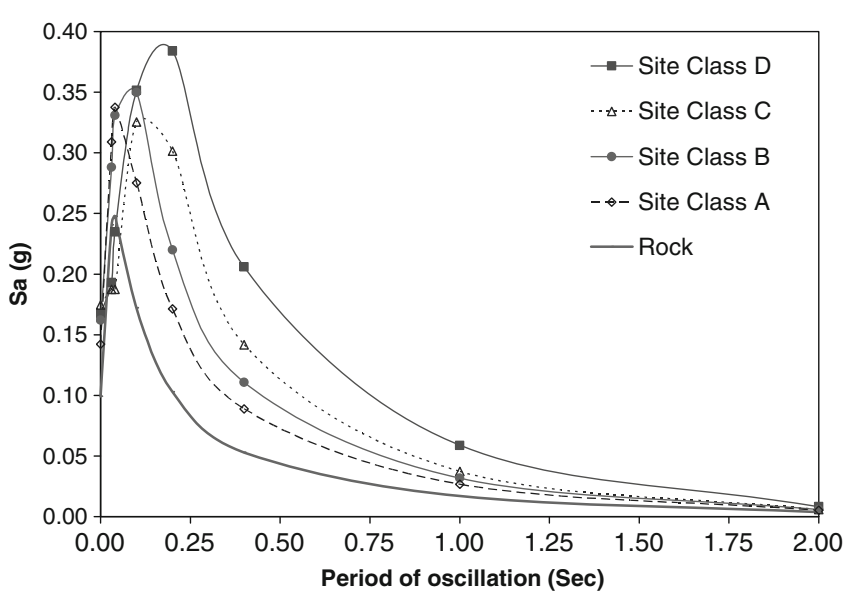

Figure 18. UHRS with $10 \%$ PE in 50 years for Chennai.

variation of predominant frequency with change in soil types. For the cities of Mumbai and Chennai, the period of oscillation corresponding to maximum Sa varies from $0.05 \mathrm{~s}$ at bedrock level to $0.2 \mathrm{~s}$ at ground surface for site class D.

The PGA values at ground surface level were evaluated for south India for $10 \%$ and $2 \% \mathrm{PE}$
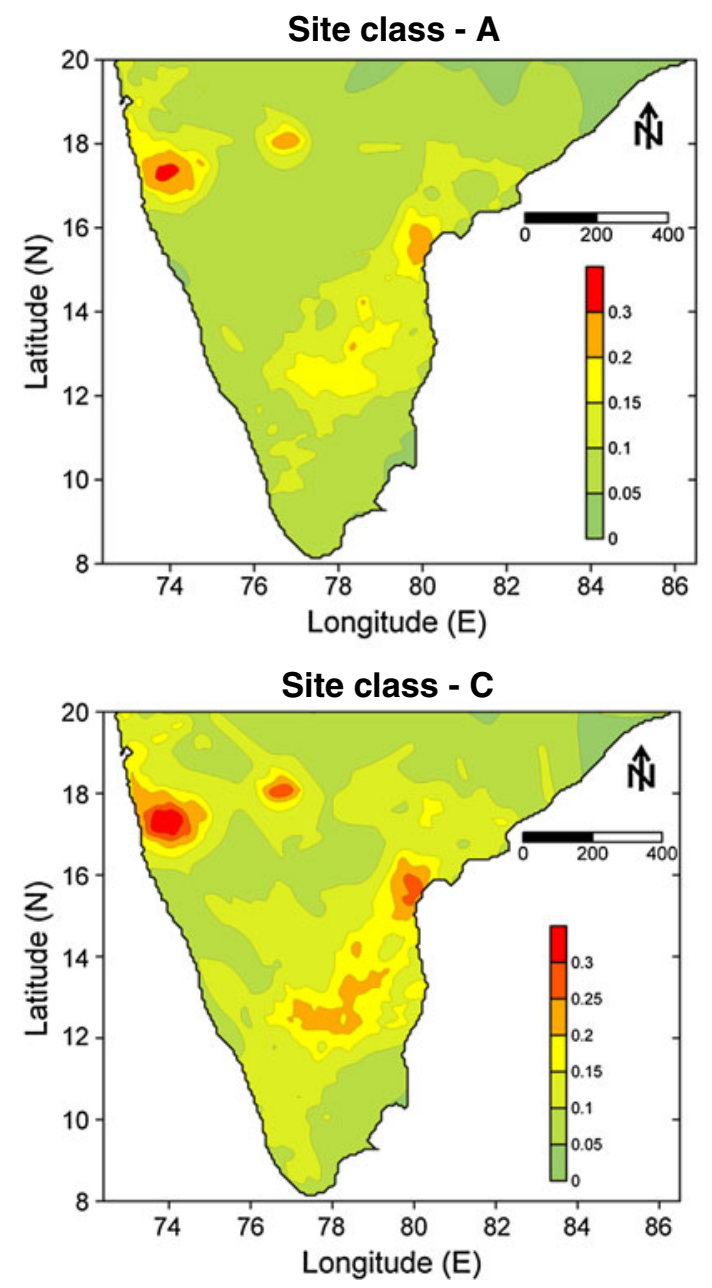

for four site classes, A-D, and are shown in figures 19 and 20. These results clearly show the effect of amplification due to overlying soil column. A geotechnical site investigation will indicate the site class (based on $V_{s}^{30}$ ) at the desired location and depending on the site class to which the site belongs, the PGA at ground surface can be obtained from the respective figures. Thus it provides a very simple and comprehensive method to obtain the PGA value for a vast area like south India.

Jaiswal and Sinha (2007) had evaluated the PHA values for peninsular India using a zone less approach. The pattern of variation of PHA values in both the studies matches well even though the PHA values obtained by Jaiswal and Sinha (2007) is less than the values obtained in this study. The main reasons for this are the difference in methods adopted for source selection, selection of attenuation relations and the increase in number of earthquake events considered in the present analysis. The PHA values obtained in this study matches well with the values obtained for Mumbai by Raghu Kanth and Iyengar (2006) and for
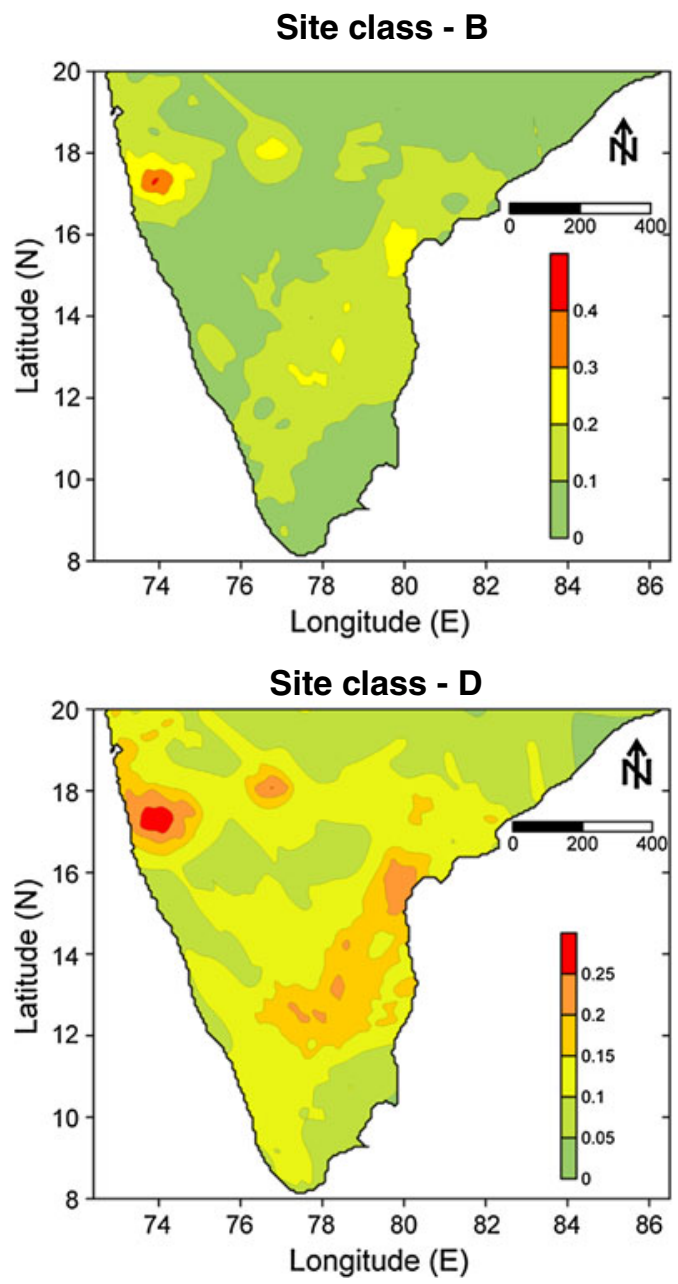

Figure 19. Variation of surface level PGA(g) for different site classes with $10 \%$ PE in 50 years. 

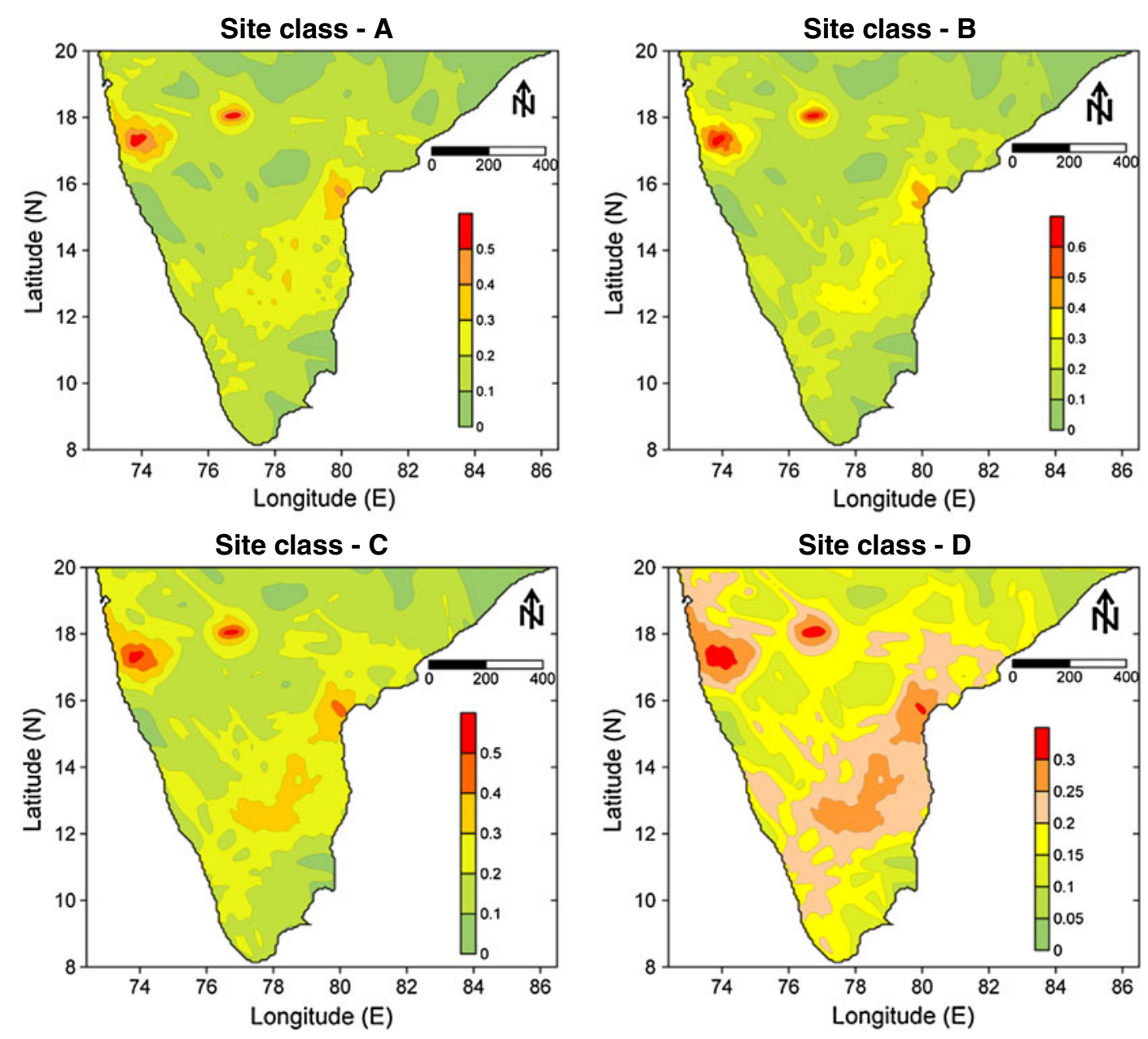

Figure 20. Variation of surface level PGA(g) for different site classes with $2 \%$ PE in 50 years.

Bangalore by Anbazhagan et al. (2009). The results obtained by Vipin et al. (2009) for south India is higher than what is obtained in this study. This is mainly because the previous study has considered (i) single type of sources (linear sources), (ii) only one attenuation relation (Raghu Kanth and Iyengar 2007) and (iii) single seismicity parameter ( $a$ and $b$ values) were used for the entire study area. In a recent study Menon et al. (2010) have evaluated the seismic hazard of Tamil Nadu based on PSHA methodology. The values obtained in the present study matches very well with the values reported by Menon et al. (2010). However, none of the previous studies had estimated the ground surface level acceleration values.

\section{Conclusions}

In the present study an attempt has been made to evaluate the seismic hazard of south India using multiple source and attenuation models. The spatial variation of $a$ and $b$ values were studied and based on this a new seismic source zonation was proposed for the study area. The probabilistic seismic hazard analysis was done for the study area by considering two different types of sources and different source zones. This will be helpful in reducing the uncertainty due to the spatial variation of seismicity parameters. The surface level acceleration values were evaluated for four site classes by considering the local site effects. If the site class at any location in the study area is known, then the ground level PGA values can be obtained based on the simplified methodology presented in this study. The PHA values obtained for some of the regions have shown significant difference from the values specified in the BIS-1893 (2002) and this needs further detailed investigation. The seismotectonic map developed in this study will be helpful for other researchers doing similar studies in south India.

\section{Acknowledgement}

Authors thank ISRO-IISc Space Technology Cell, Indian Institute of Science, Bangalore, India for 
funding the project titled 'Assessment of Seismicity of Peninsular India - Using Remote Sensing and GIS', (Ref. No. ISTC/CCE/TGS/195 Dated 7 March 2007).

\section{References}

Agrawal P K and Pandey O P 2004 Unusual lithospheric structure and evolutionary pattern of the cratonic segments of the south Indian shield; Earth Planets Space $\mathbf{5 6}$ 139-150.

Aki K 1965 Maximum likelihood estimate of $b$ in the formula $\log N=a-b M$ and its confidence limits; Bulletin of Earthquake Research Institute, University of Tokyo, 43 237-239.

Anbazhagan P, Vinod J S and Sitharam T G 2009 Probabilistic seismic hazard analysis for Bangalore; J. Nat. Hazards 48 145-166.

Atkinson G M and Boore D M 2006 Earthquake groundmotion prediction equations for Eastern North America; Bull. Seismol. Soc. Am. 96(6) 2181-2205.

Bender B 1983 Maximum likelihood estimation of $b$ values for magnitude grouped data; Bull. Seismol. Soc. Am. 73 831-851.

Bhatia S, Ravi Kumar M and Gupta H K 1997 A Probabilistic Seismic Hazard Map of India and Adjoining Regions; Annali De Geofisica 42(6) 1154-1164.

BIS-1893 2002 Indian Standard Criteria for Earthquake Resistant Design of Structures, Part 1 - General Provisions and Buildings; Bureau of Indian Standards, New Delhi.

Bommer J, Scherbaum F, Bungum H, Cotton F, Sabetta F and Abrahamson N A 2005 On the use of logic trees for ground-motion prediction equations in seismic hazard analysis; Bull. Seismol. Soc. Am. 95 377-389.

BSSC 2001 NEHRP recommended provisions for seismic regulations for new buildings and other structures, 2000 edn, part 1: Provisions, Report no. FEMA 368, Building Seismic Safety Council for the Federal Emergency Management Agency, Washington D.C., USA.

Budnitz R J, Apostolakis G, Boore D M, Cluff L S, Coppersmith K J, Cornell C A and Morris P A 1997 Recommendations for probabilistic seismic hazard analysis: Guidance on uncertainty and use of experts; U.S. Nuclear Regulatory Commission Report NUREG/ CR-6372.

Chernick M R 1999 Bootstrap methods: A practitioner's guide; Wiley Series in Probability and Statistics, Wiley, New York.

Cornell C A 1968 Engineering seismic risk analysis; Bull. Seismol. Soc. Am. 58 1583-1606.

Cramer C H and Kumar A 20032001 Bhuj, India, earthquake engineering seismoscope recordings and Eastern North America ground motion attenuation relations; Bull. Seismol. Soc. Am. 93 1390-1394.

Frank S, Bommer J J, Hilmar B, Fabrice C and Norm A Abrahamson 2005 Composite ground-motion models and logic trees: Methodology, sensitivities, and uncertainties; Bull. Seismol. Soc. Am. 95(5) 1575-1593.

Frankel A 1995 Mapping seismic hazard in the Central Eastern United States; Seismol. Res. Lett. 66(4) 8-21.

Ganesha Raj K and Nijagunappa R 2004 Major lineaments of Karnataka state and their relation to seismicity Remote sensing based analysis; J. Geol. Soc. India 63 430-439.

Gangrade B K and Arora S K 2000 Seismicity of the Indian peninsular shield from regional earthquake data; Pure Appl. Geophys. 157 1683-1705.
Gupta I D 2006 Delineation of probable seismic sources in India and neighbourhood by a comprehensive analysis of seismotectonic characteristics of the region; Soil Dynamics and Earthquake Engineering 26 766-790.

Gutenberg B and Richter C F 1944 Frequency of earthquakes in California; Bull. Seismol. Soc. Am. 34 185-188.

Iyengar R N and Ghosh S 2004 Microzonation of earthquake hazard in greater Delhi area; Curr. Sci. 87 1193-1202.

Jaiswal K and Sinha R 2007 Probabilistic seismic-hazard estimation for peninsular India; Bull. Seismol. Soc. Am. 97(1B) 318-330.

Kijko A and Sellevoll M A 1989 Estimation of earthquake hazard parameters from incomplete data files. Part I: Utilization of extreme and complete catalogs with different threshold magnitudes; Bull. Seismol. Soc. Am. 79 645-654.

Kijko A and Sellevoll M A 1992 Estimation of earthquake hazard parameters from incomplete data files. Part II: Incorporation of magnitude heterogeneity; Bull. Seismol. Soc. Am. 82 120-134.

Kiran K S T, Nath S K, Yadav A, Raj A, Yanger Walling M and Mohanty W K 2008 Recent seismicity in northeast India and its adjoining region; J. Seismol. 12 $107-123$.

Kumar P, Xiaohui Yuan, Ravi Kumar M, Rainer Kind, Xueqing Li and Chadha R K 2007 The rapid drift of Indian tectonic plate; Nature 449 894-897.

McGuire R K and Arabasz W J 1990 An introduction to probabilistic seismic hazard analysis; In: Geotechnical and Environmental Geophysics (ed.) Ward S H, Society of Exploration Geophysicist 1 333-353.

Menon A, Ornthammarath T, Corigliano M and Lai C G 2010 Probabilistic seismic hazard macrozonation of Tamil Nadu in southern India; Bull. Seismol. Soc. Am. 100 $1320-1341$.

Nath S K 2006 Seismic hazard and microzonation atlas of the Sikkim Himalaya, Department of Science and Technology, Government of India, India.

Raghu Kanth S T G and Iyengar R N 2006 Seismic hazard estimation for Mumbai city; Curr. Sci. 91(11) 1486-1494.

Raghu Kanth S T G and Iyengar R N 2007 Estimation of seismic spectral acceleration in peninsular India; J. Earth Syst. Sci. 116(3) 199-214.

Regulatory Guide 1.1651997 Identification and characterization of seismic sources and determination of safe shutdown earthquake ground motion; U.S. Nuclear Regulatory Commission.

Scordilis E M 2006 Empirical global relations converting $M_{s}$ and $m_{b}$ to moment magnitude; J. Seismol. 10 $225-236$.

Seeber L, Armbruster J G and Jacob K H 1999 Probabilistic Assessment of Seismic Hazard for Maharashtra, Govt. of Maharashtra, Unpublished Report.

SEISAT 2000 Seismotectonic Atlas of India, Geological Survey of India, New Delhi.

Sridevi J 2004 Estimates of plate velocity and crustal deformation in the Indian subcontinent using GPS geodesy; Curr. Sci. 86 1443-1448.

Stepp J C 1972 Analysis of the completeness of the earthquake sample in the Puget Sound area and its effects on statistical estimates of earthquakes hazard; Proceedings of the International Conference on Microzonation, Seattle, Washington 64(4) 1189-1207.

Stepp J C, Wong I, Whitney J, Quittemeyer R, Abrahamson N, Toro G, Youngs R, Coppersmith K, Savy J and Sullivan T 2001 Yucca Mountain PSHA Project Members, Probabilistic seismic hazard analyses for ground motions 
and fault displacements at Yucca Mountain, Nevada; Earthquake Spectra 17 113-151.

Toro G N, Abrahamson N and Schneider J 1997 Model of strong ground motions from earthquakes in central and eastern North America: Best estimates and uncertainties; Seismol. Res. Lett. 68 41-57.

Utsu T 1965 A method for determining the value of $b$ in a formula $\log n=a-b M$ showing the magnitude-frequency relation for earthquakes; Geophys. Bull. Hokkaido Univ. 13 99-103 (in Japanese).

Utsu T 1999 Representation and analysis of the earthquake size distribution: A historical review and some new approaches; Pure Appl. Geophys. 155 509-535.
Valdiya K S 1973 Tectonic framework of India: A review and interpretation of recent structural and tectonic studies; Geophys. Res. Bull. 11 79-114.

Vipin K S, Anbazhagan P and Sitharam T G 2009 Estimation of peak ground acceleration and spectral acceleration for south India with local site effects: Probabilistic approach; Nat. Hazards Earth Syst. Sci. 9 865-878.

Wiemer S 2001 A software package to analyze seismicity: zmap; Seismol. Res. Lett. 72(2) 374-383.

Wiemer S and Wyss M 2000 Minimum magnitude of complete reporting in earthquake catalogs: Examples from Alaska, the Western United States and Japan; Bull. Seismol. Soc. Am. 90 859-869. 